\title{
Numerical approach for structural analysis of Metro tunnel station
}

\author{
Mirzakhid Miralimov", Shahboz Normurodov, Mirali Akhmadjonov, and Abdullaziz \\ Karshiboev \\ Tashkent State Transport University, Tashkent, Uzbekistan
}

\begin{abstract}
In this paper is presented the results of calculations of reinforced concrete structure of metro station in the form of cupola located at the intersection of interstation tunnels. The constructive solution of station is economical, allows diversifying its architecture and using the internal space for placing objects of the national economy. One of the important design stages is the assessment of the stress-strain state of structure with different boundary conditions when it is exposed to external loads. It is assumed that deformable environment surrounding the tunnel station is elastic and is modeled by discrete bearing reaction located in contact with the station. The structure is modeled by finite shell elements. As the result of calculation the principal stresses and moments in its sections are determined. The obtained data can be made by designers in determining of structural solution, dimensions and initial sections selection of reinforcement elements.
\end{abstract}

\section{Introduction}

The significant increase in construction quantities of metro tunnels requires the meaningful expanding of capacities of scientific-technical potential. The scientific and technological progress of industry is characterized by such indicators as the level of industrialization of construction with the use of effective structures and methods of their design [1-3].

The engineering experience in the construction of tunnels in areas of high seismicity calls for the design of reliable structures (operating without loss of bearing capacity in conditions of possible tectonic displacements of soil masses and earthquakes), all time process of improving the design schemes of interstation and station tunnels, taking into account adaptation to the changed conditions of the new facility, carried out in accordance with the general principles of earthquake-resistant construction [4-6].

The constructive solution of metro station, which received a patent № 4386 can be used at the intersection crossing of interstation tunnels [7]. Thin-walled spatial structure of the vault and its location at intersection of tracks in the center of station increases the costeffectiveness of construction (Figure 1). The station contains vault 1 as in the form of thinwalled cupola with strengthened heel 2, platforms and tracks of one and another line 3, which intersect in the center of the station. The $1 / 2-1 / 3$ of height of cupola comes to the surface of the ground. Such constructive solution of station on the crossing line is

\footnotetext{
*Corresponding author: mirzakhid_miralimov@yahoo.com
} 
economical and allows diversifying the architecture of station use its internal space for the placement of national economic objects.

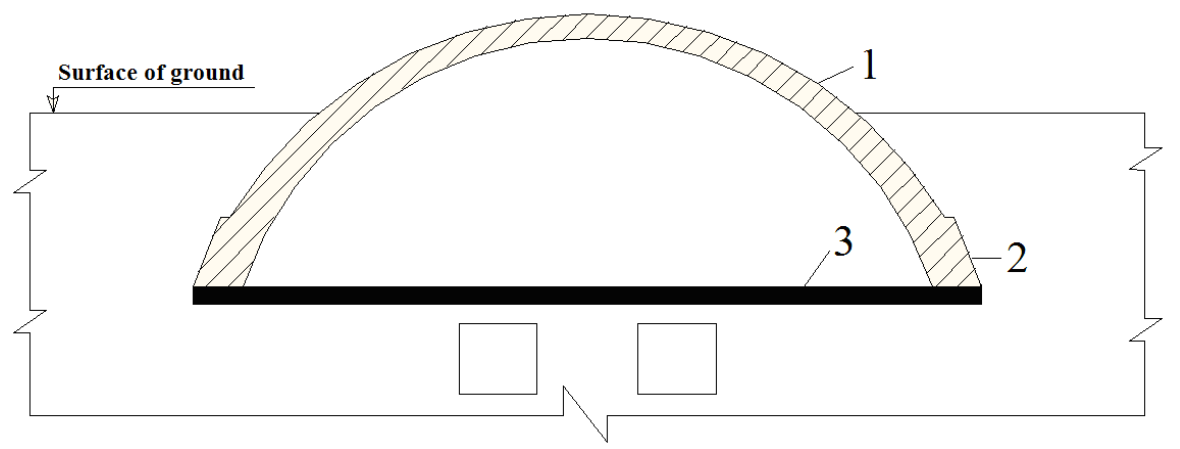

Fig. 1. The view of station at the crossing of interstation tunnels

\section{Methods}

In contrast to cupola cover the trough element together with the support ring form strong structure, which perceives the thrust of arch. The shell part of cupola structure is made by prefabricated elements of ribbed plates, 55 and $40 \mathrm{~cm}$ thick (Figure 2).

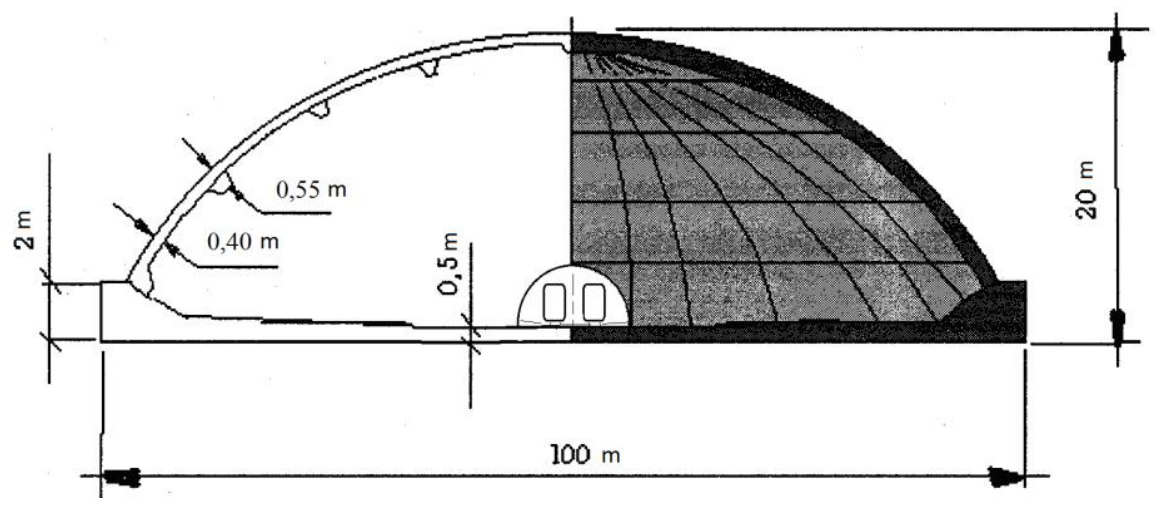

Fig. 2. General view of station

The trough part can be made as precast or precast-monolithic structure [8-10]. Prefabricated elements are connected by welding of reinforcement outlets with formwork concreting as the result of which the seismic belt of high rigidity is created $[11,12]$. However, the vault can be rigidly or hingedly supported on strengthened heel of plate (trough part). For the passage of paired trains of one and the other direction, the vault can have a cutout on four sides as shown in figure 2 .

At the same time the material of station is reinforced concrete with following data: the modulus of elasticity and density of reinforced concrete structure are $31500 \mathrm{MPa}, 0.025$ $\mathrm{MN} / \mathrm{m}^{3}$, the density and friction angle of soil are $0.018 \mathrm{MN} / \mathrm{m}^{3}, 26^{\circ}$. For physical modeling of station we are used the shell triangular finite element with 5 degrees of freedom at each node [13-15].

Based on experience of construction of shallow tunnels we consider three real depths of the bed of structure from ground surface, equal with step of $20 \mathrm{~m}$. To identify most 
unfavorable loading of the structure, we take into account the bearing reaction only in the lower part of station vault with the interaction coefficient $\mathrm{k}_{\mathrm{z}}=50 \mathrm{MPa} / \mathrm{m} \mathrm{[16]}$. We also consider the behavior of cupola structure with rigid and hinged support of its ends. The effective loads on structure are obtained from the dead weight of structure and weight of proper soil layer taking into account with quasi-static seismic load (vertical and lateral) [17]. On calculating by the finite element method the structure is divided into n nodes and $\mathrm{m}$ triangular shell elements. Then, according to [18] each node has 5 degrees of freedom and for each i-th node we can take the vector of nodal displacements in the form: $\vec{Z}_{i}=\left[U_{i}, V_{i}, W_{i}, \varphi_{i}^{X}, \varphi_{i}^{Y}\right]^{T}$ (Figure 3). The general equilibrium equations expressed through the shell stiffness matrix according to [19] cane is written in the form:

$$
(K+\bar{K}) \vec{Z}=\vec{P}
$$

where: $K, K, \vec{Z}, \vec{P}$ are matrix of stiffness of the finite element system, matrix of interaction with soil, vectors of displacements and nodal forces. The system of equation (1) is solved by the automated way with element-by-element approach.

The stiffness matrix of the system is the quadratic matrix, positive definite and band. Due to symmetry the PC memory can store only half of the matrix including the main diagonal. The element stiffness matrix in the local coordinate system has the order of $15 \times 15$. The derivation of this matrix is given in $[19,20]$.
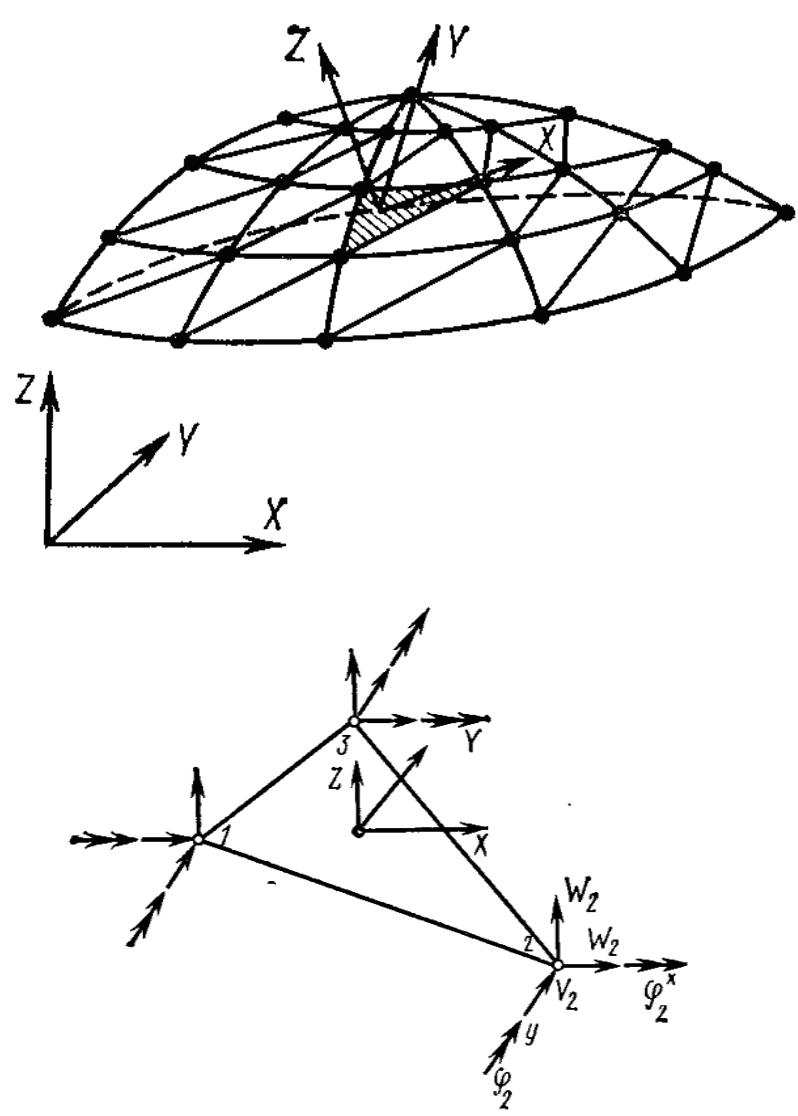

Fig. 3. Cupola with shell triangular elements 
The triangles into which the shell-lining is split can have an arbitrary orientation. Therefore, to compose the reaction matrix in equation (1) it is necessary to transfer the stiffness matrix from the local system to the general transformation [C] through the matrix in the form:

$$
\begin{aligned}
& {[K]=[C]^{\mathrm{T}}[k][C]} \\
& {[C]=\left[\begin{array}{lll}
c & 0 & 0 \\
0 & c & 0 \\
0 & 0 & c
\end{array}\right], \quad[c]=\left[\begin{array}{ccc}
\cos \alpha & \sin \alpha & 0 \\
-\sin \alpha & \cos \alpha & 0 \\
0 & 0 & 1
\end{array}\right]}
\end{aligned}
$$

\section{Results and Discussion}

In figure 4 is showed the finite element meshes of the cupola, where the system has 2995 elements and 6606 degrees of freedom.

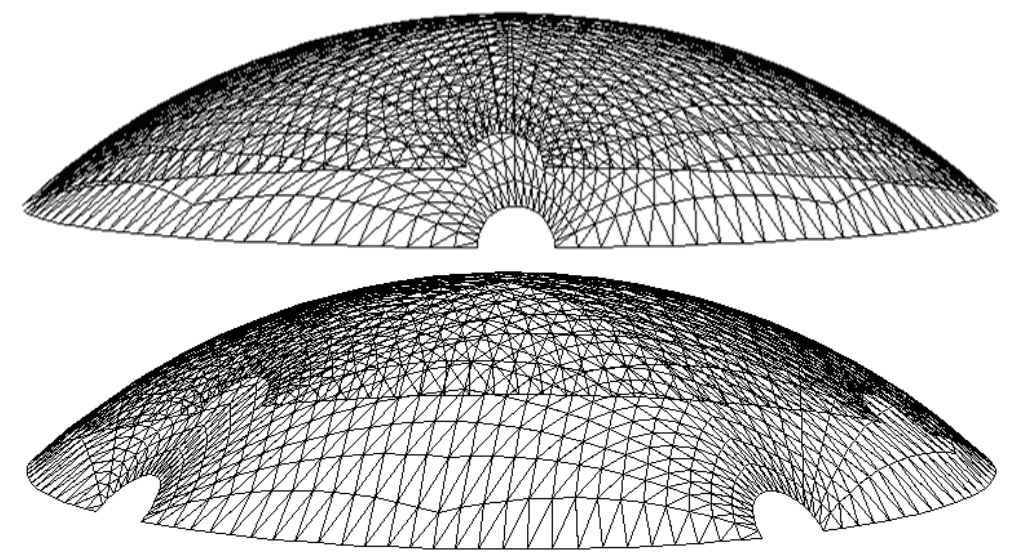

Fig. 4. The finite element scheme of cupola station

a)

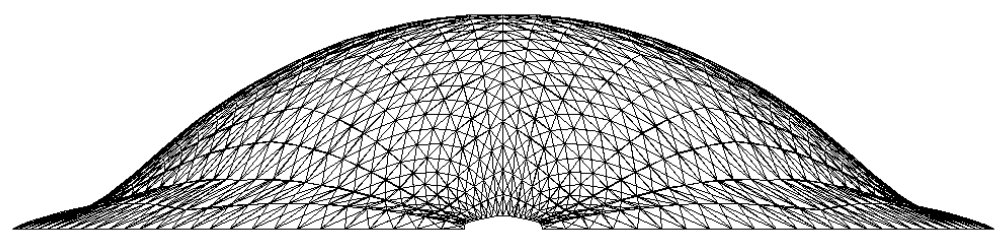


b)

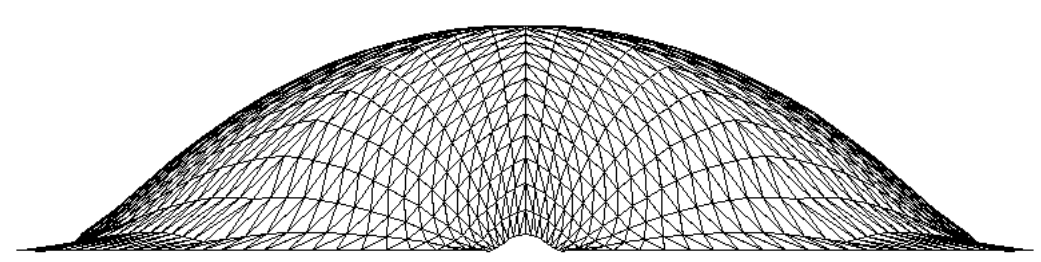

Fig. 5. The deformation of cupola station: a - with rigid support at edges, $b$ - with hinged support at edges
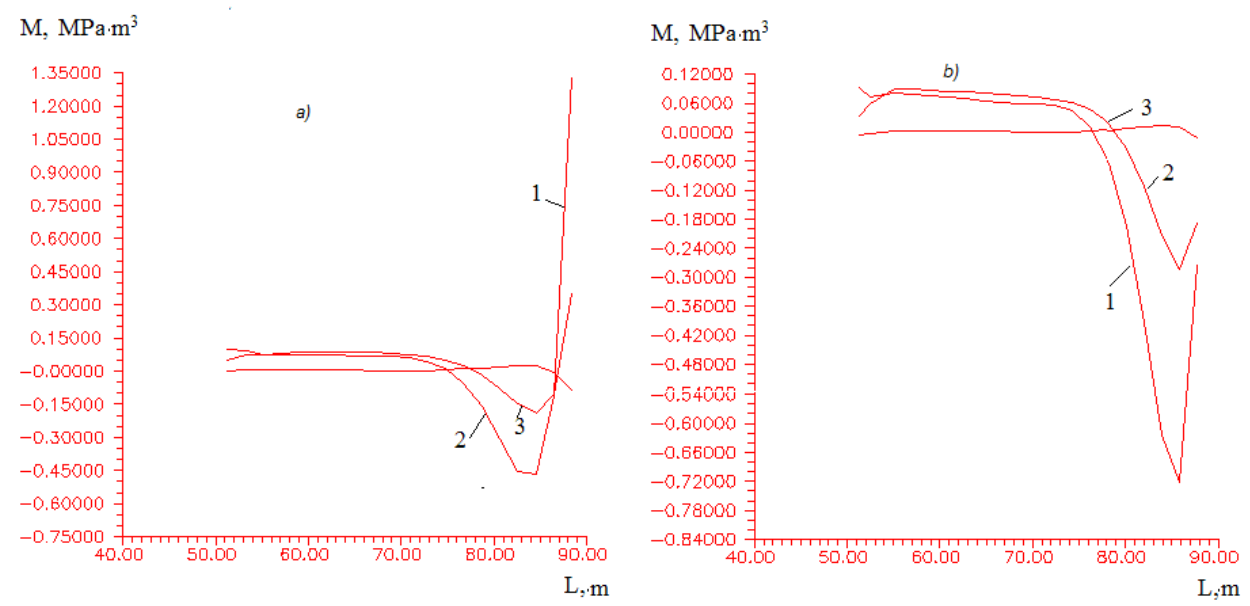

Fig. 6. Changes of moments from edge to center: 1 is radial moment, 2 is ring moment, 3 is longitudinal force, $\mathrm{a}$ - with rigid fixing of the edges, $\mathrm{b}$ - with hinge fixing of the edges

The figure 5 shows the patterns of deformation of the cupola for two boundary conditions. Observing them we can see a general similarity, however, in the places of support and near the cutouts they are deformed differently. Here, it can be seen that maximum radial moments and longitudinal forces are obtained at the heel of station, i.e. at the junction of trough element with cupola. Radial moments are greater than ring ones. After a sharp jump, approaching the center, the radial and ring moments decrease (Figure $6)$. 

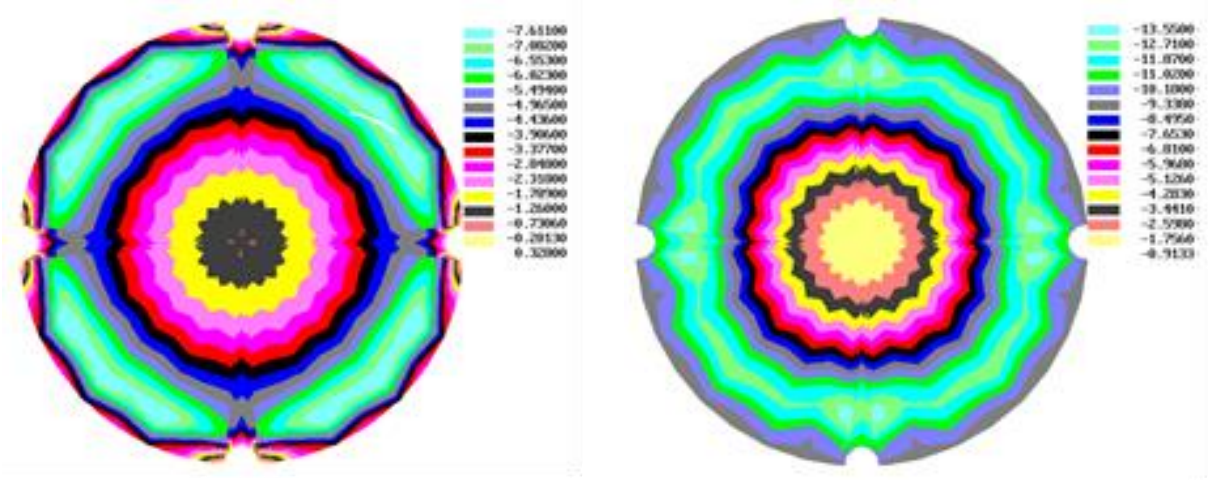

Fig. 7. Isochromes of principal stresses $\sigma_{I}$ and $\sigma_{2}$ in cupola with rigid fixing of the edges, (MPa)
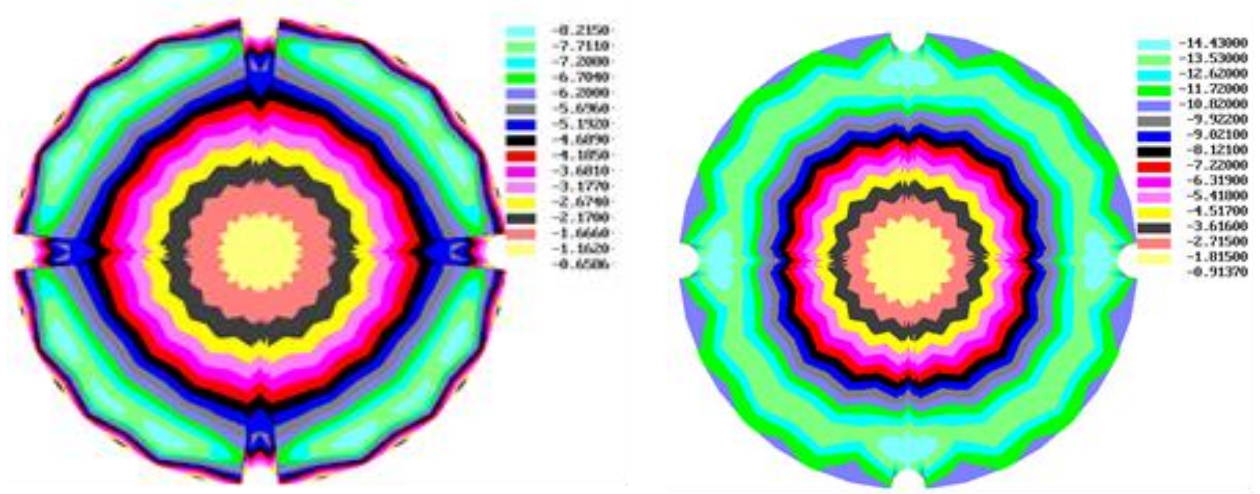

Fig. 8. Isochromes of principal stresses $\sigma_{1}$ and $\sigma_{2}$ in cupola with hinge fixing of the edges, MPa)
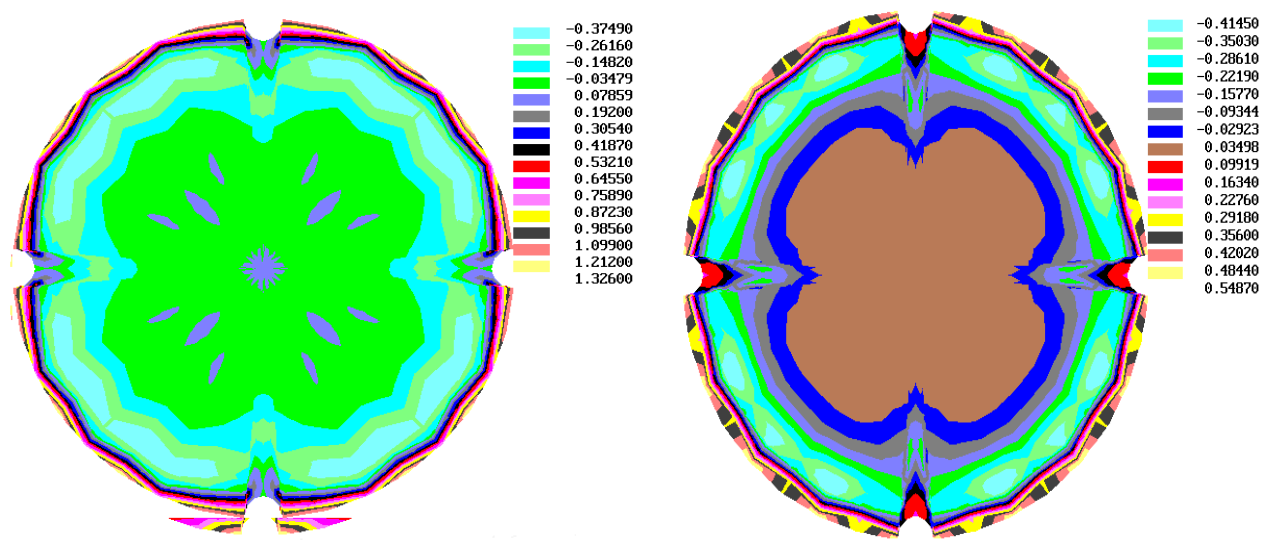


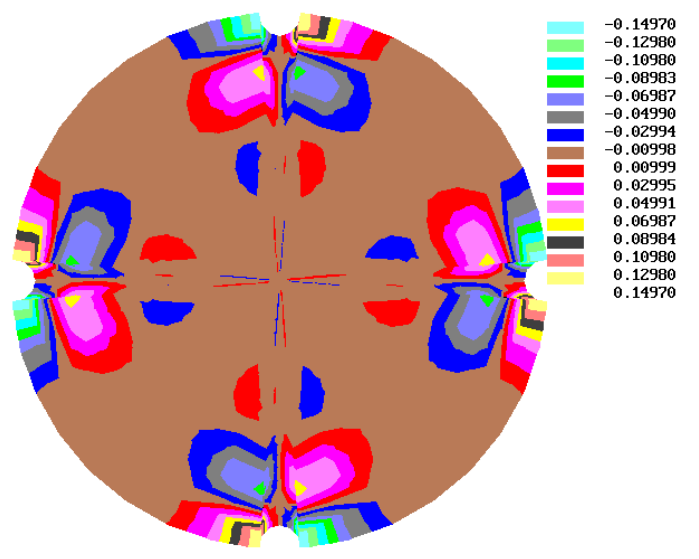

Fig. 9. Isochromes of moments $\mathrm{Mx}, \mathrm{My}$ and $\mathrm{Mz}$ in cupola with rigid fixing of the edges, $\left(\mathrm{MPa} \cdot \mathrm{m}^{3}\right)$
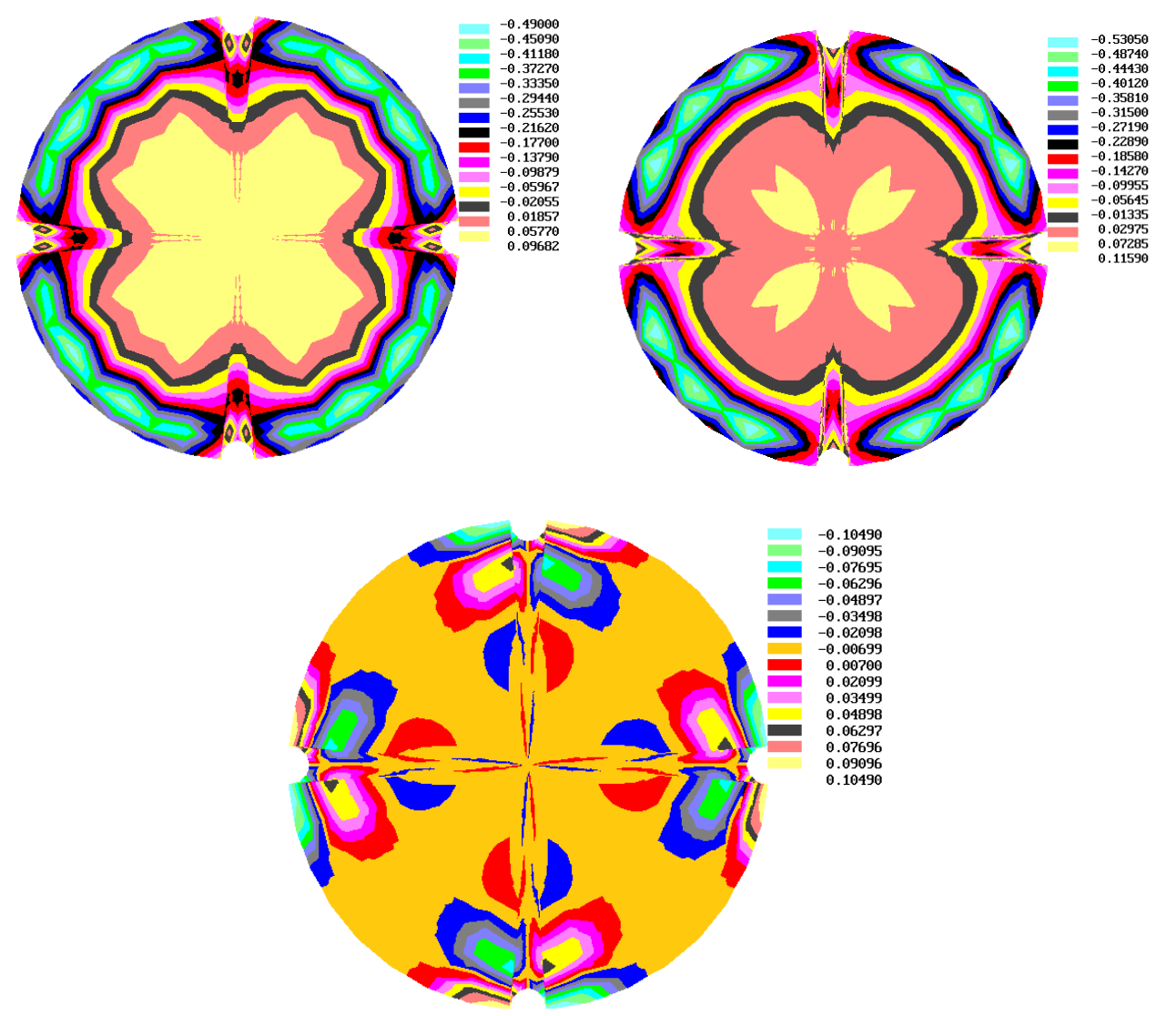

Fig. 10. Isochromes of moments $\mathrm{Mx}, \mathrm{My}$ and $\mathrm{Mz}$ in cupola with hinge fixing of the edges, $\left(\mathrm{MPa} \cdot \mathrm{m}^{3}\right)$

In figures 7,8 are show the change in the principal stresses $\sigma_{1}$ and $\sigma_{2}$ in the cupola with different fixing of the edges. At figures 9, 10 are given the changes of the moments with account of central nodes of each finite elements in direction of $\mathrm{x}, \mathrm{y}$ and $\mathrm{z}$. 


\section{Conclusions}

The obtained results of calculations of reinforced concrete structure of metro station in the form of cupola located at the intersection of interstation tunnels is allowed to assessment of stress-strain state of structure with different boundary conditions The analysis of distribution of stresses and moments in structure implies to reduction crosssection in the middle part of cupola and the significant increase in the places of their connection fixing ends. On selecting reinforcing bars at fixing location, it is necessary to take into account changes in the signs of moments in the radial and ring directions.

\section{References}

1. Francesca N, Giuseppe V. Strengthening of reinforced concrete beams with basaltbased FRP sheets: An analytical assessment, AIP Conference Proceedings 1738, 1, 270016, (2016), https:// doi.org/10.1063/1.4952055

2. Gorbushin N., Eremeyev V. A., Mishuris G. On stress singularity near the tip of a crack with surface stresses. International Journal of Engineering Science, 146, 103183, 1-17. (2019), https:// doi.org/10.1016/j.ijengsci.2019.103183

3. Colombo M., Martinelli P., Di Prisco, M. (2015). A design approach for tunnels exposed to blast and fire. Structural Concrete, 16(2), pp. 262-272. doi:10.1002/suco.201400052

4. Shoaei M., Maddahin R., Afshin H., Farhanie B. Designing Fire Scenarios for Subway Stations and Tunnels Based on Regional Approach. Advanced Materials Research Vols. 433-440, 983-991, doi.org/10.4028/www.scientific.net/AMR.433-440.983

5. Zhang Z.X., Chao L., Huang X., Kwok F. Three-dimensional finite-element analysis on ground responses during twin-tunnel construction using the URUP method. Tunnelling and Underground Space Technology, 58, pp. 133-146, (2016), doi.10.1016/j.tust.2016.05.001

6. Sherif A. Mazek. N. Evaluation of surface displacement equation due to tunnelling in cohesionless soil. Geomechanics and Engineering, 7(1), pp. 55-73, (2014) doi. 10.12989/gae.2014.7.1.055

7. Miralimov M. (2019). Improvement of constructive decisions, calculation methods of transport and underground tunnel linings. Dissertation abstract of doctor of sciences (DSc)

8. Nariman N. Prediction Meta-Models for the Responses of a Circular Tunnel During Earthquakes. Underground Space, (2018), https://doi. 10.1016/j.undsp.2018.06.003

9. Dawood T., Zayed T. (2020). Deterioration mapping in subway infrastructure using sensory data of GPR. Tunnelling and Underground Space Technology. 103. https:// doi.org/10.1016/j.tust.2020.103487

10. Chen Z., Zhang Y., Li J., Li X., Jing L. Diagnosing tunnel collapse sections based on TBM tunneling big data and deep learning: A case study on the Yinsong Project, China. Tunnelling and Underground Space Technology, 108. (2021), https:// doi.org/10.1016/j.tust.2020.103700

11. Cai, Y., Jiang, Y., Djamaluddin, I., Iura, T., and Esaki, T. An analytical model considering interaction behavior of grouted rock bolts for convergence-confinement method in tunneling design. International Journal of Rock Mechanics and Mining Sciences, 76, pp.112-126, (2015), doi: 10.1016/j.ijrmms.2015.03.006

12. Caratelli A., Meda A., Rinaldi Z., Spagnuolo S. Precast tunnel segments with GFRP reinforcement. Tunnelling and Underground Space Technology, 60, pp. 10-20. (2016). doi: 10.1016/j.tust.2016.07.011 
13. Di Carlo F., Meda A., Rinaldi Z. Design procedure for precast fibre-reinforced concrete segments in tunnel lining construction. Structural Concrete, 17(5), pp. 747759. (2016), doi.10.1002/suco.201500194

14. Dmitriev A., Lalin V., Novozhilov Yu., Mikhalyuk D. Simulation of Concrete Plate Perforation by Coupled Finite Element and Smooth Particle Hydrodynamics Methods; 2020; Construction of Unique Buildings and Structures; 92; Article No 9207. doi: 10.18720/CUBS.92.7

15. Dmitriev A., Novozhilov Y., Mikhalyuk D., Lalin V. Calibration and Validation of the Menetrey-Willam Constitutive Model for Concrete; Construction of Unique Buildings and Structures; 88; Article No 8804. (2020), doi:10.18720/CUBS.88.4

16. Lalin V.V, Dmitriev A., Diakov S. Nonlinear deformation and stability of geometrically exact elastic arches; Magazine of Civil Engineering, 89(5), pp. 39-51. (2019), DOI: 10.18720/MCE.89.4

17. Huang Q., Huang H., Ye B., Zhang D., Gu L., Zhang F. Dynamic response and longterm settlement of a metro tunnel in saturated clay due to moving train load. 10591075, 57, (2017), https:// doi.org/10.1016/j.sandf.2017.08.031

18. Mirsaidov M., Sultanov T. Z. Assessment of stress-strain state of earth dams with allowance for non-linear strain of material and large dams. Mag. Civ. Eng 49(5) p. 73-82, (2014).

19. Oreste P.P. A Numerical Approach to the Hyperstatic Reaction Method for the Dimensioning of Tunnel Supports Tunn. Undergr. Sp.Technol. (2007), doi.org/10.1016/j.tust.2006.05.00

20. Miralimov M. Kh. Strength Calculation Method of Reinforced Concrete Structures of Tashkent Underground Tunnels with Different Stages of Stress Condition. IOP Conf. Ser. Mater. Sci. Eng. (2019), doi.org/10.1088/1757-899X/615/1/012083 